\title{
Biological behavior of different Trypanosoma cruzi isolates circulating in an endemic area for Chagas disease in the Gran Chaco region of Argentina
}

\author{
Paula G. Ragone a,b,*, Cecilia Pérez Brandán ${ }^{\mathrm{b}}$, Angel M. Padilla ${ }^{\mathrm{c}}$, Mercedes Monje Rumi ${ }^{\mathrm{a}, \mathrm{b}}$, \\ Juan J. Lauthier ${ }^{\mathrm{a}, \mathrm{b}}$, Anahí M. Alberti D’Amato ${ }^{\mathrm{a}, \mathrm{b}}$, Nicolás Tomasini ${ }^{\mathrm{a}, \mathrm{b}}$, Ruben O. Cimino ${ }^{\mathrm{d}}$, \\ Nélida M. Romero ${ }^{\mathrm{e}}$, Marcela Portelli ${ }^{\mathrm{d}}$, Julio R. Nasser ${ }^{\mathrm{d}}$, Miguel A. Basombrío ${ }^{\mathrm{b}}$, Patricio Diosque ${ }^{\mathrm{a}, \mathrm{b}}$ \\ a Unidad de Epidemiología Molecular, Instituto de Patología Experimental, CONICET, Universidad Nacional de Salta, Argentina \\ ${ }^{\mathrm{b}}$ Instituto de Patología Experimental, CONICET, Universidad Nacional de Salta, Argentina \\ ${ }^{\mathrm{c}}$ Center for Tropical and Emerging Global Diseases, University of Georgia, Athens, GA, USA \\ d Cátedra de Química Biológica, Universidad Nacional de Salta, Argentina \\ e Cátedra de Zoología, Universidad Nacional de Salta, Argentina
}

\section{A R T I C L E I N F O}

\section{Article history:}

Received 20 December 2011

Received in revised form 8 May 2012

Accepted 14 May 2012

Available online 27 May 2012

\section{Keywords:}

Trypanosoma cruzi

Chagas disease

Natural isolates

Biological properties

\begin{abstract}
A B S T R A C T
The biological behavior of the different Trypanosoma cruzi strains is still unclear and the importance of exploring the relevance of these differences in natural isolates is of great significance. Herein we describe the biological behavior of four $T$. cruzi isolates circulating sympatrically in a restricted geographic area in Argentina endemic for Chagas Disease. These isolates were characterized as belonging to the Discrete Typing Units (DTUs) TcI, TcIII, TcV and TcVI as shown by Multilocus Enzyme Electrophoresis and Multilocus Sequence Typing. In order to study the natural behavior of the different isolates and to preserve their natural properties, we developed a vector transmission model that allows their maintenance in the laboratory. The model consisted of serial passages of these parasites between insect vectors and mice. Vector-derived parasite forms were then inoculated in C57BL/6J mice and number of parasite in peripheral blood, serological response and histological damage in acute and chronic phases of the infection were measured. Parasites from DTUs TcI, TcIII and TcVI were detected by direct fresh blood examination, while TcV parasites could only be detected by Polimerase Chain Reaction. No significant difference in the anti-T. cruzi antibody response was found during the chronic phase of infection, except for mice infected with $\mathrm{TcV}$ parasites where no antibodies could be detected. Histological sections showed that TcI isolate produced more damage in skeletal muscle while TcVI induced more inflammation in the heart. This work shows differential biological behavior among different parasite isolates obtained from the same cycle of transmission, permitting the opportunity to formulate future hypotheses of clinical and epidemiological importance.
\end{abstract}

(ㄷ) 2012 Elsevier B.V. All rights reserved.

\section{Introduction}

Chagas disease affects several million people in Latin America and still remains an important public health problem in certain endemic areas of Argentina. Trypanosoma cruzi, the etiologic agent of Chagas disease, shows a high genetic variability. Based on its genetic diversity, T. cruzi has been classified into six Discrete Typing Units (DTUs), TcI to TcVI (Zingales et al., 2012). Most of this well-known genetic variability correlates with the phenotypic heterogeneity observed in natural populations of this parasite

\footnotetext{
* Corresponding author at: Unidad de Epidemiología Molecular, Instituto de Patología Experimental, CONICET, Universidad Nacional de Salta, Avenida Bolivia 5150, Salta 4400, Argentina. Tel.: +54 387 4255333; fax: +54 3874255333 .

E-mail address: p_ragone@yahoo.com.ar (P.G. Ragone).
}

(Andrade, 1999; Revollo et al., 1998). Under that hypothesis, several studies were carried out, generating information about the behavior of T. cruzi in cell cultures (Laurent et al., 1997; Revollo et al., 1998), insect vectors (de Lana et al., 1998; Pinto et al., 1998), experimental animals (de Lana et al., 1998; dos Santos et al., 2009; Lisboa et al., 2007; Martins et al., 2006; Toledo et al., 2002) and susceptibility to different trypanomicidal drugs in vitro and in vivo (Revollo et al., 1998; Toledo et al., 2003). The differences observed in the DTUs might act as a determinant factor in the clinical course of Chagas disease (Burgos et al., 2010; del Puerto et al., 2010b; Ramirez et al., 2010).

The genetic diversity of both parasite and host is the main determinant of what is known as the "clonal histotropic model" of Chagas disease (Macedo et al., 2004). It has been proposed that $T$. cruzi has a predominant clonal evolution (Tibayrenc et al., 1986); suggesting a possible correlation between biological differences and genetic 
divergence among T. cruzi natural clones. This population structure has epidemiological and clinical implications because different "clones" are believed to be stable units which may be associated with particular biological properties (Toledo et al., 2002).

In Chaco Province, Argentina, there are areas where active vectorial transmission still exists and the presence of three different T. cruzi DTUs was detected (Diosque et al., 2003). Here we describe the biological properties of different $T$. cruzi strains isolated from different hosts from an endemic area of Chaco Province, Argentina.

\section{Materials and methods}

\subsection{Trypanosoma cruzi isolates and genetic characterization}

T. cruzi isolates were obtained from natural reservoirs captured in Las Leonas settlement (W61 $39^{\prime} 8.7^{\prime \prime}$, S27 $01^{\prime} 49^{\prime \prime}$ ), located southwest of Chaco Province, Argentina. All samples were obtained within an area of approximately $140 \mathrm{~km}^{2}$. In this settlement transmission active sites were found, with a domiciliary infestation of $82.25 \%$. In this study area a seroprevalence of $40 \%$ was found in humans, while the prevalence in dog was $11.97 \%$ (Alberti et al., personal communication). Parasites were recovered from the feces of either naturally infected Triatoma infestans or insects that were fed on mammalian hosts (Xenodiagnosis). T. cruzi DTUs were identified by Multilocus Enzyme Electrophoresis (MLEE) using the following enzyme systems: Glucose-6-Phosphate Isomerase (GPI), Leucyl Aminopeptidase (LAP) and Superoxide Dismutase (SOD) (Ben Abderrazak et al., 1993). Isolates were also identified by Multilocus Sequence Typing (MLST) using fragments from the following genes: Rho-like gtp binding protein (RHO1), Glucose-6-Phosphate Isomerase (GPI) and Small gtp-binding protein rab7 (GTP) (Lauthier et al., 2011). Reference strains for each lineage: X10 cl1, OPS21 cl11 (DTU TcI); TU18 cl93, IVV cl4 (DTU TcII); M5631 cl5, M6241 cl6 (DTU TcIII); CANIII cl1, Dog Theis (DTU TcIV); Mn cl2, Sc43 cl1 (DTU TcV); CL Brener, P63 cl1 (DTU TcVI), were used in parallel for the DTU determination. Based on these results one isolate of each DTU was selected for the study.

\subsection{Maintenance of T. cruzi isolates: vector transmission model}

With the purpose of preventing attenuation due to successive in vitro culturing, we developed, for each isolate, a transmission model in which the parasites were maintained through serial passages between insect vectors and mice. The parasites were obtained from the feces of naturally infected insects and from those used for xenodiagnosis. To initiate the vector transmission model, these parasites were injected into $\mathrm{C} 57 \mathrm{BL} / 6 \mathrm{~J}$ mice. Twenty days postinoculation, mice were subjected to xenodiagnosis, using third instar nymphs of Triatoma infestans. After 30 days, insect feces were examined microscopically and the recovered parasites were injected again into naïve mice. Natural isolates continue to be maintained following this procedure.

\subsection{Experimental infection in mice}

Groups of 5 male C57BL/6J mice (one month old) were inoculated for each one of the isolates under study. These groups were done in duplicate in order to describe the biological properties at two different time points: 32 days (acute phase) and 120 days (chronic phase). Inoculation was carried out by intraperitoneal (i.p.) route with $10^{4}$ parasites/mouse recovered from the feces of infected insects used in the model described above. Control groups inoculated with Phosphate Buffer Saline (PBS) were included in the experiment. Animal care guidelines adopted by the Health
Sciences Faculty, National University of Salta, Argentina, were strictly followed.

\subsection{Parasitological and PCR determinations}

Blood from inoculated animals was collected in heparinized glass capillary pipettes by sectioning the tail tip under slight anesthesia. Ten microliters $(\mu \mathrm{l})$ of blood were placed between slide and cover slip and the number of parasites per 100 fields was recorded microscopically $(40 \times)$ twice a week. Polymerase chain reaction (PCR) assays was performed when mice were negative for parasitemia. In those cases peripheral blood $(350 \mu \mathrm{l})$ of injected animals was taken and mixed with 2 volumes of guanidine buffer. DNA extraction was carried out from $100 \mu \mathrm{l}$ of the mix by phenol-chloroform method. Subsequent amplification of the hypervariable region of minicircles was performed using primers 121 and 122 (Britto et al., 1993). Those animals with negative PCR were considered as not infected and discarded from the experiment analysis.

\subsection{Serological determinations}

Antibody production was evaluated by serology using the Enzyme Linked Immunosorbent Assay (ELISA). Serum samples were collected at 32 and 120 days post-infection (dpi). A serum dilution of $1 / 100$ was used against total $T$. cruzi antigens from an epimastigotes homogenate obtained from the Tulahuen strain of T. cruzi according to standardized protocols (Nasser et al., 1997). Optical density values were measured at $490 \mathrm{~nm}$.

\subsection{Histopathology}

Animals were sacrificed at 30 and $120 \mathrm{dpi}$ by exposure to halothane. Heart and skeletal muscle were collected and fixed in $10 \%$ formalin and processed using routine histological techniques. Serial histological sections (3-5 $\mu \mathrm{m}$ thick), were stained with hematoxylin-eosin and observed under microscope (50, 100 and $400 \times$ ). Quantification of the inflammatory response (IR) was assessed taking into account the presence or absence of inflammatory foci and foci intensity. A criterion was set according to the size and number of foci in order to quantify the inflammatory process in different organs. Thus, IR was quantified blindly as null (no presence of foci or inflammatory cells); mild (presence of small and isolated inflammatory foci); moderate (major inflammatory foci containing inflammatory cells and presence of isolated foci and diffuse inflammatory cells throughout the sample); and severe (presence of foci containing numerous inflammatory cells covering a high percentage of the sample and interconnected with each other by isolated cells). In some cases intermediate values for the inflammatory response were admitted: slight increase in mononuclear cells, mild to moderate and moderate to severe.

\subsection{Statistical analysis}

One-way variance analysis (ANOVA) or Mann-Whitney $U$ tests were used to compare the number of parasites in peripheral blood, antibody levels and the inflammatory response. To analyze inflammatory response numeric values for the different levels were assigned: null: 0 , slight increase in mononuclear cells: 0.5 ; mild: 1; mild to moderate: 2 ; moderate: 3 ; moderate to severe: 4 ; and severe: 5. Statistical analysis was performed using the software GraphPad Prism V5.00. 
A

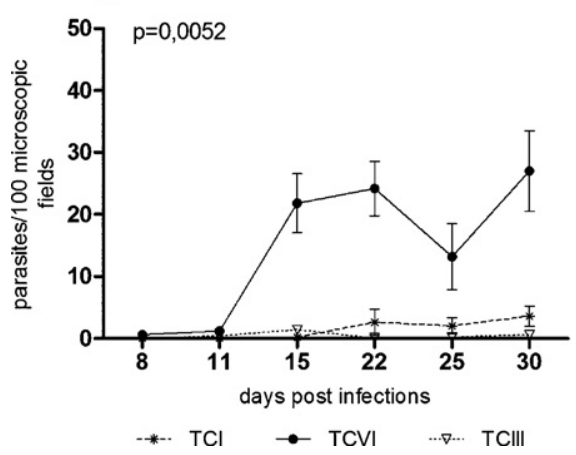

B

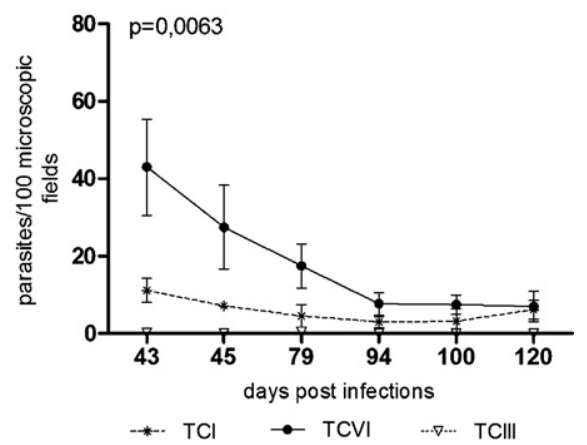

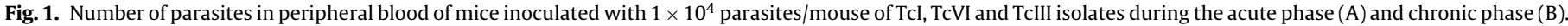

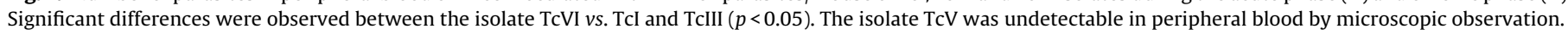

\section{Results}

\subsection{Trypanosoma cruzi DTU diversity in the study area}

Molecular characterization results showed that the isolates circulating in the study area belonged to 4 out of the $6 \mathrm{~T}$. cruzi DTUs described so far. MLEE and MLST analysis characterized the isolates as DTUs TcI, TcIII, TcV and TcVI; with a concordance of $100 \%$ between these two techniques. Thus, 4 isolates were selected, one for each detected T. cruzi DTU. The isolates were: LL027-21(TcI), LL051-P24 (TcIII), LL014-1 (TcV) and LL040-1 (TcVI). The isolates belonging to TcV and TcVI were obtained from intradomiciliary $T$. infestans; TcI was obtained from peridomiciliary T. infestans; while TcIII was obtained from a dog (Canis familiaris). Hereafter, isolates will be named according to the corresponding DTU.

\subsection{Parasite detection}

To examine the presence of parasites in pheripheral blood, two groups of mice per isolate were inoculated as described in Section 2. One group was evaluated on days $8-30$ post-infection and the other group was evaluated on days 43-120 post-infection. Both acute and chronic phases mice infected with TcVI isolate showed the highest number of circulating parasites, as compared to mice infected with either isolates TcI or TcIII $(p<0.05)$ (Fig. 1A-B). However, the differences in the number of parasites between TcI-infected and TcIII-infected mice was not significantly different $(p>0.05)$. In the case of animals inoculated with isolate $\mathrm{TcV}$ direct microscopic observation in peripheral blood was unable to detect parasites and infection was only accomplished by PCR in 3 out of 5 animals in each group in both the acute and chronic phases.

\section{A}

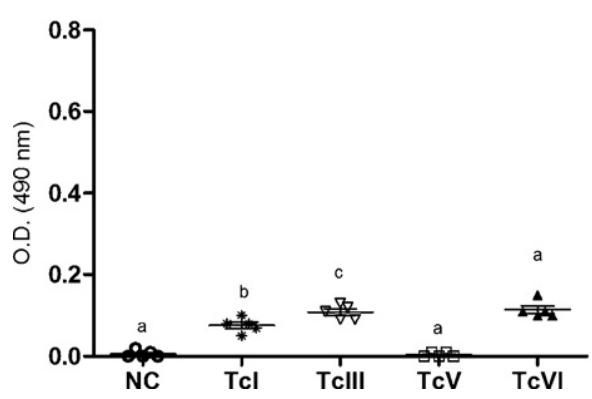

\subsection{Anti-T. cruzi antibodies}

At day 30 post-infection, the antibody levels in mice infected with TcI, TcIII and TcVI differed significantly from the response obtained from non-infected mice $(p<0.05)$ (Fig. 2A). The antibody level in TcI-infected animals was significantly lower than in TcIIIinfected and TcVI-infected mice $(p<0.05)$. In these last two groups the response was similar $(p>0.05)$. In animals infected with isolate $\mathrm{TcV}$, no antibody response against $T$. cruzi could be detected at that point in time. From samples taken during the chronic phase of infection (day 120) a highly significant difference in the antibody level of mice infected with TcI, TcIII and TcVI was observed compared to the antibody level of non-infected mice $(p<0.01)$ (Fig. 2B). In animals inoculated with isolate TcV no significant differences in anti-T. cruzi antibody levels were detected at 120 days post-infection compared with non-infected animals.

\subsection{Inflammatory response during the acute phase}

Skeletal muscle. A severe inflammatory response (IR) induced by the isolate TcI was observed, where large interconnecting inflammatory foci, nuclear dysplasia and homogenization of the muscle fibers were detected (Fig. 3A). In animals infected with TcVI parasites, a moderate IR was detected. We were able to detect amastigotes nests in 3 out of 5 mice (60\%) from this group (Fig. 3B). Mice infected with the TcIII isolate showed mild lesions (Fig. 3C); while those infected with $\mathrm{TcV}$ parasites did not present any significant IR with the exception of one mouse showing mild lesions (data not shown). The remaining mice showed just a slight increase in mononuclear cells. Statistical differences $(p<0.05)$ were observed between TcI vs. TcIII, TcI vs. TcV and TcVI vs. TcV (Fig. 4A).

Cardiac muscle. The TcVI isolate induced more damage in this tissue compared to the other isolates, which had moderate to severe

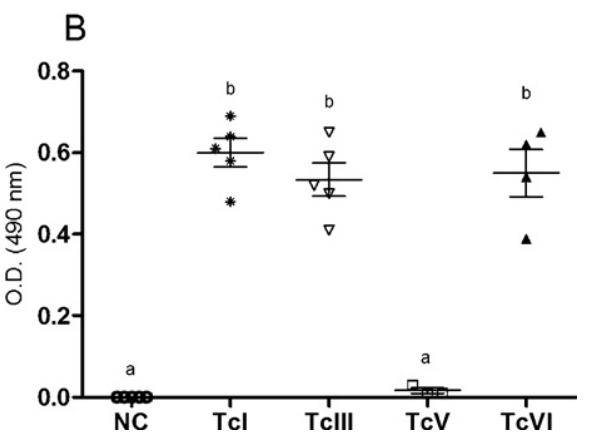

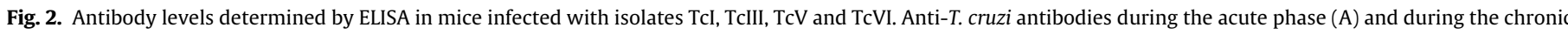
phase (B). Different letters indicate significant differences $(p<0.05)$. NC, negative control (non infected mice). 

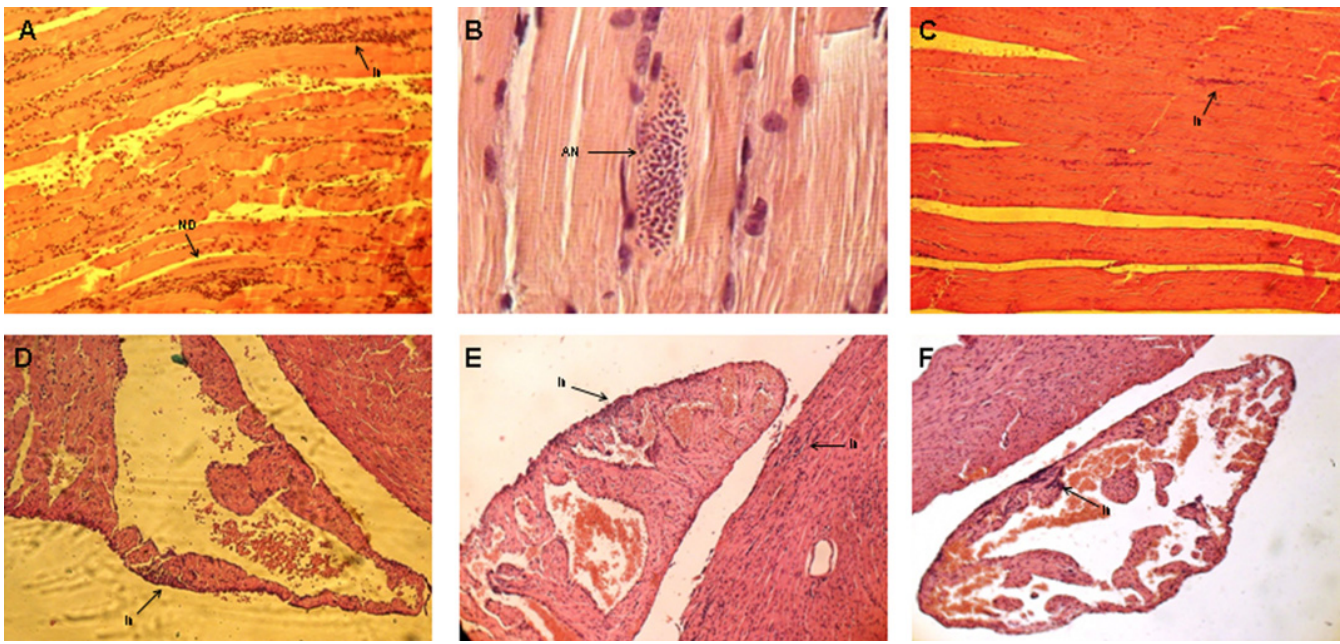

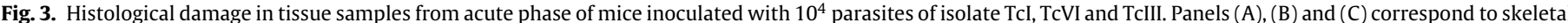

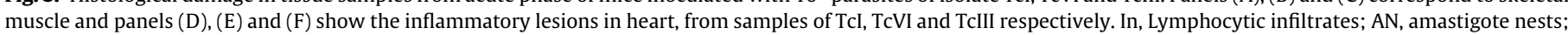
ND, nuclear dysplasia.

lesions. Also, an intense myocarditis with traces of active inflammatory activity and atrioventricular pericarditis was detected (Fig. 3E); in animals infected with the other isolates the damage observed was lower. Mice infected with TcIII exhibited a moderate, predominantly atrioventricular IR (Fig. 3D), while mice infected with TcI showed mainly mild IR with inflammatory foci concentrated in the atrium (Fig. 3D). In TcV-infected mice no response was detected in this tissue. When comparing the IR induced in the heart by the different isolates, statistically significant differences were found between TcI $v s$. TcVI and between TcI $v s$. TcIII $(p<0.05)$ (Fig. 4B).

\subsection{Inflammatory response during the chronic phase}

Skeletal muscle. When analyzing this tissue in samples taken during the chronic phase of the disease, no significant differences among the isolates under study were detected (Fig. 5A). Animals infected with TcI showed mild to moderate lesions; in this case no cellular damage or amastigotes nests were detected. Similar was the case of mice infected with the TcVI isolate, where a mild to moderate response, with few inflammatory foci dispersed in the tissue surface analyzed and without cellular damage, was observed (data not shown). Mice infected with TcIII showed mild lesions and a slight increase in mononuclear cells. Again, no damage or inflammatory response was observed in animals infected with $\mathrm{TcV}$ in this tissue.

Cardiac muscle. From heart samples examined, the major damage was caused by TcVI, exhibiting mild to moderate lesions mostly in the atrial and interventricular septum. The animals infected with
TcIII showed mild lesions, while those infected with TcI showed mainly a slight increase in mononuclear cells. In this tissue, significant differences between TcVI vs. TcI isolates were observed $(p<0.05)$ (Fig. 5B). Again, no damage or IR was observed in animals infected with $\mathrm{TcV}$.

\section{Discussion}

The knowledge and comprehension of the genetic diversity within $T$. cruzi has increased enormously since pioneering work by Miles (Miles et al., 1977, 1981) and Tibayrenc (Tibayrenc et al., 1985, 1993, 1986; Tibayrenc and Desjeux, 1983). However, one of the major expected consequences of the observed diversity within T. cruzi, i.e. correlation of the genetic diversity with biological properties, has not been unequivocally established.

The aim of this work was to describe the biological properties of isolates belonging to the main T. cruzi DTUs circulating sympatrically in an endemic region of Argentina (TcI, TcIII, TcV and TcVI). We developed an experimental model involving maintenance of these isolates by serial passages between insect vectors ( $T$. infestans) and mammal hosts (C57BL/6J mice), without in vitro culture. The purpose of maintaining these isolates circulating between insect vectors and mammalian hosts was to avoid major alterations of their biological properties, which is known to occur when parasites are cultured in vitro. The outcomes obtained regarding differences in the number of parasites in peripheral blood, levels of anti-T. cruzi specific antibodies and inflammatory response in targeted tissues
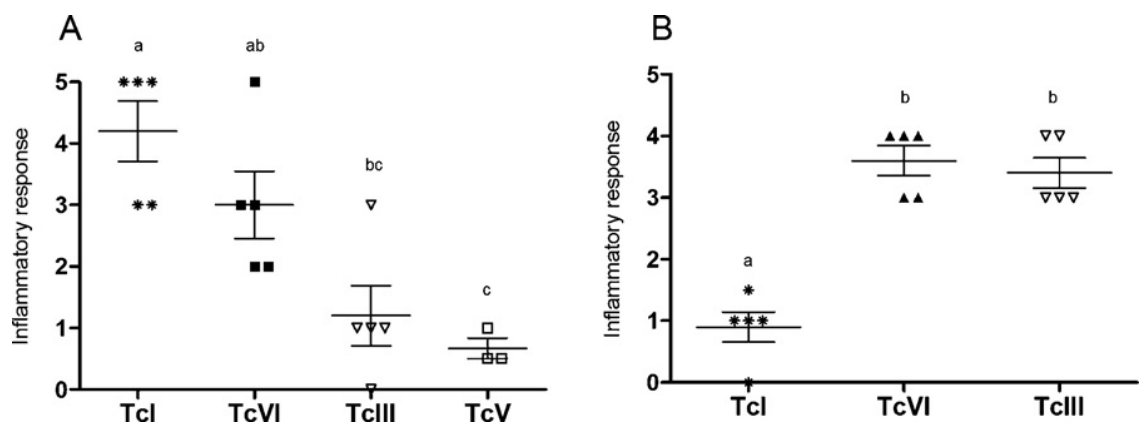

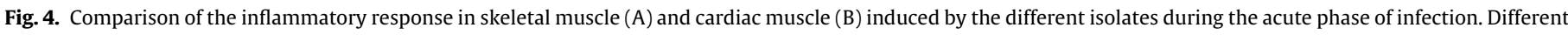
letters indicate significant differences $(p<0.05)$ 

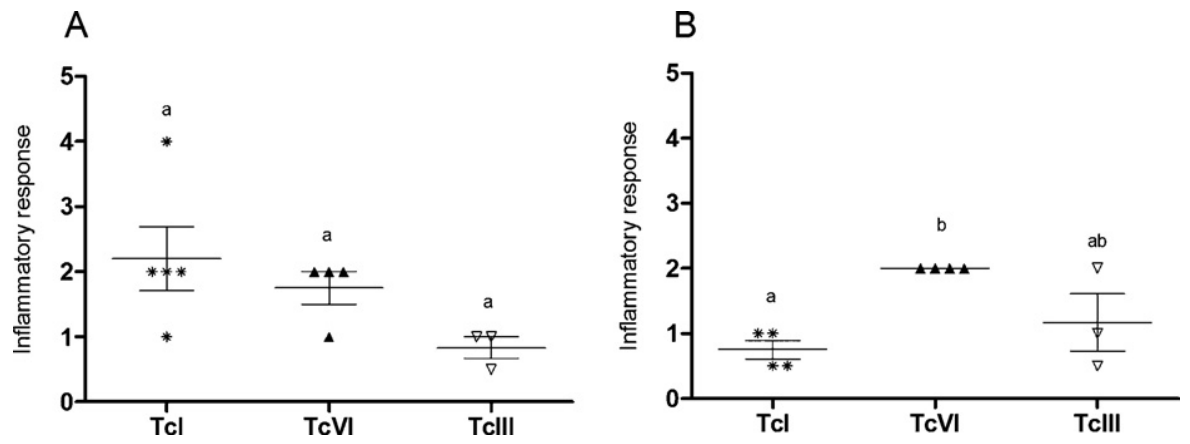

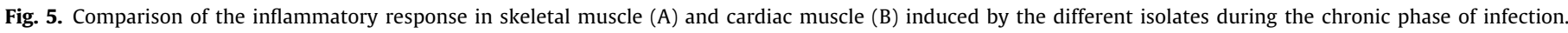
Differences were only detected in cardiac muscle between isolates TcI and TcVI $(p<0.05)$.

led us to conclude that evident biological differences among the isolates under study do occur.

Most of the isolates presented evident parasitemia, being the level of circulating parasites in peripheral blood higher in mice infected with the TcVI isolate. However, in mice inoculated with the $\mathrm{TcV}$ isolate, parasite's presence could only be detected by highly sensitive molecular methods. These opposite behaviors are relevant since it would allow us to hypothesize about the parasite availability to insect vectors circulating in the endemic area. However, we have to keep in mind that an improved ability to replicate and circulate in vertebrate hosts does not always directly correlate with maintaining these same properties in vector hosts. Several factors like parasite complement mediated lysis, replication rates, ability to invade different target tissues, among others, should also be taken into consideration.

It is known that the ability of $T$. cruzi to colonize host cells and ensure survival depends on several factors. To outlive the acute phase, the mammalian host develops a parasite-specific response that efficiently reduces parasite load in tissues and blood. In the current study no striking differences in the concentration of anti-T. cruzi antibodies elicited by mice infected with the different isolates were detected, except for those infected with TcV. Curiously, the animals infected with $\mathrm{TcV}$ (PCR positive) showed no antibody response during the acute or chronic phase. It has been reported that there are some $T$. cruzi strains that are also not good inducers of humoral responses (Basombrio et al., 2002). Even more, there may be other experimental conditions (i.e. inoculums of parasites, age and strain of mice) that could have influenced this outcome. In this sense, our results are interesting from the point of view that some isolates obtained from humans belong to this particular DTU (Cardinal et al., 2008; Corrales et al., 2009; Diosque et al., 2003). This is in concordance with published works, where seronegative patients have a positive PCR result (Mora et al., 2005; Salomone et al., 2003). Therefore, some cases of human infection by T. cruzi based on conventional serology might not be properly detected.

On the other hand, attempts to show association of some $T$. cruzi DTUs with the cardiac form of Chagas disease in humans have not yet been conclusive (Zingales et al., 2012). In Argentina, recent investigations conducted on biological samples of patients presenting chagasic cardiac complications revealed the presence of TcI, TcV and TcVI and possibly TcII (Burgos et al., 2010; Cura et al., 2012). The results mentioned above indicate that all these DTUs may be present in patients suffering the cardiac form of Chagas disease, but no association analysis could be done due to the scarce number of samples available. The fact that in our study we found significant differences between isolates belonging to the more prevalent DTUs circulating in our study area (TcV and TcVI), suggests that, even if the biological behavior of these isolates were different in humans than in mice, we could expect differential clinical manifestations in patients infected by each of these DTUs.
Trypanosoma cruzi parasites belonging to DTU TcIII has been commonly reported in the silvatic transmission cycle (Llewellyn et al., 2009a; Marcili et al., 2009). Recently the presence of this lineage in humans infections has been sporadically reported (del Puerto et al., 2010a; Marcili et al., 2009; Ramirez et al., 2010). Herein, we define TcIII as an emerging DTU in the domestic cycle of transmission in the Chaco Province. The presence of this lineage in Argentina has been previously reported by Cardinal et al. (2008) supporting this finding. Considering its recent detection, the clinical manifestations induced by this lineage are still unknown, therefore, we believe that the study of this isolate deserves more attention; especially owing to the observed cardiac damage detected in the experimental animals of this study.

In another context, the inflammatory process in cardiac muscle induced by the TcI isolate was not significant and this agreed with information previously reported by another author (Andrade, 1999). However, this is in controversy with the findings of Toledo et al. (2002) who observed severe myocarditis in mice infected with DTU TcI (named genotypes 19 and 20). At this point it is important to highlight the subdivision existing within TcI, since a high genetic intraspecific variability has been reported (Herrera et al. 2009; Llewellyn et al., 2009b; Messenger et al., 2012; Ramirez et al., 2010; Tomasini et al., 2011). Furthermore, some studies suggest the existence of differences in the histotropism of parasites belonging to Tcla and TcId (Burgos et al., 2010; Zafra et al., 2011).

Although the extrapolation of infection results obtained from animal models was inconclusive regarding the natural occurrence of the phenomena in other hosts, we believe that the differences in the biological proprieties among the studied isolates undoubtedly could influence both the epidemiological and clinical patterns in the study area. We maintain that the results obtained in this work are important as it allows us to formulate hypotheses that could guide the design of molecular epidemiology studies in the study area. It is also necessary to outline that in natural cycles there are other variables involved, such as human genetic diversity and interactions among different $T$. cruzi DTUs and genotypes, which could constitute multiclonal populations with selective advantageous associations.

Finally, we emphasize the importance of future studies focused on the biological behavior of these isolates in co-infection studies under the assumption that they could interact and modify the intrinsic behavior of individual isolates, inducing different biological properties, or altering the transmission dynamics in the study area.

\section{Acknowledgments}

This work was supported by the Institute of Development Research, France, the European Union Seventh Framework Programme, contract number 223034 (ChagasEpiNet) and National 
Agency for Promotion of Science and Technology, Argentina (PICT32308). Technical help provided by Alejandro Uncos and Federico Ramos as well as statistical advice by Ruben Cardozo were highly appreciated.

\section{References}

Andrade, S.G., 1999. Trypanosoma cruzi: clonal structure of parasite strains and the importance of principal clones. Memorias do Instituto Oswaldo Cruz 94 (Suppl. 1), 185-187.

Basombrio, M.A., Segura, M.A., Nasser, J.R., 2002. Relationship between long-term resistance to Trypanosoma cruzi and latent infection, examined by antibody production and polymerase chain reaction in mice. Journal of Parasitology 88 1107-1112.

Ben Abderrazak, S., Guerrini, F., Mathieu-Daude, F., Truc, P., Neubauer, K., Lewicka, K., Barnabe, C., Tibayrenc, M., 1993. Isoenzyme electrophoresis for parasite characterization. Methods in Molecular Biology 21, 361-382.

Britto, C. Cardoso, M.A., Wincker, P., Morel, C.M., 1993. A simple protocol for the physical cleavage of Trypanosoma cruzi kinetoplast DNA present in blood samples and its use in polymerase chain reaction (PCR)-based diagnosis of chronic Chagas disease. Memorias do Instituto Oswaldo Cruz 88, 171-172.

Burgos, J.M., Diez, M., Vigliano, C., Bisio, M., Risso, M., Duffy, T., Cura, C., Brusses, B., Favaloro, L., Leguizamon, M.S., Lucero, R.H., Laguens, R., Levin, M.J., Favaloro, R., Schijman, A.G., 2010. Molecular identification of Trypanosoma cruzi discrete typing units in end-stage chronic Chagas heart disease and reactivation after heart transplantation. Clinical Infectious Diseases 51, 485-495.

Cardinal, M.V., Lauricella, M.A., Ceballos, L.A., Lanati, L., Marcet, P.L., Levin, M.J. Kitron, U., Gurtler, R.E., Schijman, A.G., 2008. Molecular epidemiology of domestic and sylvatic Trypanosoma cruzi infection in rural northwestern Argentina. International Journal for Parasitology 38, 1533-1543.

Corrales, R.M., Mora, M.C., Negrette, O.S., Diosque, P., Lacunza, D., Virreira, M. Breniere, S.F., Basombrio, M.A., 2009. Congenital Chagas disease involves Trypanosoma cruzi sub-lineage IId in the northwestern province of Salta, Argentina. Infection, Genetics and Evolution 9, 278-282.

Cura, C.I., Lucero, R.H., Bisio, M., Oshiro, E., Formichelli, L.B., Burgos, J.M., Lejona, S., Bruses, B.L., Hernandez, D.O., Severini, G.V., Velazquez, E., Duffy, T., Anchart, E., Lattes, R., Altcheh, J., Freilij, H., Diez, M., Nagel, C., Vigliano, C., Favaloro, L. Favaloro, R.R., Merino, D.E., Sosa-Estani, S., Schijman, A.G., 2012. Trypanosoma cruzi discrete typing units in Chagas disease patients from endemic and nonendemic regions of Argentina. Parasitology 139, 516-521.

de Lana, M., da Silveira Pinto, A., Barnabe, C., Quesney, V., Noel, S., Tibayrenc, M. 1998. Trypanosoma cruzi: compared vectorial transmissibility of three major clonal genotypes by Triatoma infestans. Experimental Parasitology 90, 20-25.

del Puerto, F., Sanchez, Z., Nara, E., Meza, G., Paredes, B., Ferreira, E., Russomando, G., 2010a. Trypanosoma cruzi lineages detected in congenitally infected infants and Triatoma infestans from the same disease-endemic region under entomologic surveillance in Paraguay. American Journal of Tropical Medicine and Hygiene 82, 386-390.

del Puerto, R., Nishizawa, J.E., Kikuchi, M., Iihoshi, N., Roca, Y., Avilas, C., Gianella, A., Lora, J., Velarde, F.U., Renjel, L.A., Miura, S., Higo, H., Komiya, N., Maemura, K., Hirayama, K., 2010b. Lineage analysis of circulating Trypanosoma cruzi parasites and their association with clinical forms of Chagas disease in Bolivia. PLoS Neglected Tropical Diseases 4, e687.

Diosque, P., Barnabe, C., Padilla, A.M., Marco, J.D., Cardozo, R.M., Cimino, R.O., Nasser J.R., Tibayrenc, M., Basombrio, M.A., 2003. Multilocus enzyme electrophoresis analysis of Trypanosoma cruzi isolates from a geographically restricted endemic area for Chagas' disease in Argentina. International Journal for Parasitology 33, 997-1003.

dos Santos, D.M., Talvani, A., Guedes, P.M., Machado-Coelho, G.L., de Lana, M., Bahia, M.T., 2009. Trypanosoma cruzi: genetic diversity influences the profile of immunoglobulins during experimental infection. Experimental Parasitology $121,8-14$.

Herrera, C., Guhl, F., Falla, A., Fajardo, A., Montilla, M., Adolfo Vallejo, G., Bargues, M.D., 2009. Genetic variability and phylogenetic relationships within Trypanosoma cruzi I Isolated in Colombia based on Miniexon gene sequences. Journal of Parasitology Research.

Laurent, J.P., Barnabe, C., Quesney, V., Noel, S., Tibayrenc, M., 1997. Impact of clonal evolution on the biological diversity of Trypanosoma cruzi. Parasitology $114(\mathrm{Pt}$ 3), 213-218.

Lauthier, J.J., Tomasini, N., Barnabe, C., Monje Rumi, M.M., Alberti D’Amato, A.M. Ragone, P.G., Yeo, M., Lewis, M.D., Llewellyn, M., Basombrio, M.A., Miles, M.A. Tibayrenc, M., Diosque, P., 2011. Candidate targets for multilocus sequence typing of Trypanosoma cruzi: validation using parasite stocks for the Chaco region and a set of reference strains. Infection, Genetics and Evolution.

Lisboa, C.V., Pinho, A.P., Monteiro, R.V., Jansen, A.M., 2007. Trypanosoma cruzi (kinetoplastida Trypanosomatidae): biological heterogeneity in the isolates derived from wild hosts. Experimental Parasitology 116, 150-155.

Llewellyn, M.S., Lewis, M.D., Acosta, N., Yeo, M., Carrasco, H.J., Segovia, M., Vargas, J., Torrico, F., Miles, M.A., Gaunt, M.W., 2009a. Trypanosoma cruzi IIc: phylogenetic and phylogeographic insights from sequence and microsatellite analysis and potential impact on emergent Chagas disease. PLoS Neglected Tropical Diseases 3, e510.

Llewellyn, M.S., Miles, M.A., Carrasco, H.J., Lewis, M.D., Yeo, M., Vargas, J., Torrico, F., Diosque, P., Valente, V., Valente, S.A., Gaunt, M.W., 2009b. Genome-scale multilocus microsatellite typing of Trypanosoma cruzi discrete typing unit I reveals phylogeographic structure and specific genotypes linked to human infection. PLoS Pathogens 5, e1000410.

Macedo, A.M., Machado, C.R., Oliveira, R.P., Pena, S.D., 2004. Trypanosoma cruzi: genetic structure of populations and relevance of genetic variability to the pathogenesis of Chagas disease. Memorias do Instituto Oswaldo Cruz 99, $1-12$.

Marcili, A., Lima, L., Valente, V.C., Valente, S.A., Batista, J.S., Junqueira, A.C., Souza, A.I., da Rosa, J.A., Campaner, M., Lewis, M.D., Llewellyn, M.S., Miles, M.A., Teixeira, M.M., 2009. Comparative phylogeography of Trypanosoma cruzi TCIIc: new hosts, association with terrestrial ecotopes, and spatial clustering. Infection, Genetics and Evolution 9, 1265-1274.

Martins, H.R., Toledo, M.J., Veloso, V.M., Carneiro, C.M., Machado-Coelho, G.L., Tafuri, W.L., Bahia, M.T., Valadares, H.M., Macedo, A.M., Lana, M., 2006. Trypanosoma cruzi: impact of dual-clone infections on parasite biological properties in BALB/C mice. Experimental Parasitology 112, 237-246.

Messenger, L.A., Llewellyn, M.S., Bhattacharyya, T., Franzen, O., Lewis, M.D., Ramirez, J.D., Carrasco, H.J., Andersson, B., Miles, M.A., 2012. Multiple mitochondrial introgression events and heteroplasmy in Trypanosoma cruzi revealed by Maxicircle MLST and next generation sequencing. PLoS Neglected Tropical Diseases 6, e1584.

Miles, M.A., Cedillos, R.A., Povoa, M.M., de Souza, A.A., Prata, A., Macedo, V., 1981. Do radically dissimilar Trypanosoma cruzi strains (zymodemes) cause Venezuelan and Brazilian forms of Chagas' disease? Lancet 1,1338-1340.

Miles, M.A., Toye, P.J., Oswald, S.C., Godfrey, D.G., 1977. The identification by isoenzyme patterns of two distinct strain-groups of Trypanosoma cruzi, circulating independently in a rural area of Brazil. Transactions of the Royal Society of Tropical Medicine and Hygiene 71, 217-225.

Mora, M.C., Sanchez Negrette, O., Marco, D., Barrio, A., Ciaccio, M., Segura, M.A., Basombrio, M.A., 2005. Early diagnosis of congenital Trypanosoma cruzi infection using PCR, hemoculture, and capillary concentration, as compared with delayed serology. Journal of Parasitology 91, 1468-1473.

Nasser, J.R., Gomez, L.E., Sanchez, D., Guerin, M., Basombrio, M.A., 1997. Immunogenicity of the recombinant SAPA protein of Trypanosoma cruzi for mice. Journal of Parasitology 83, 76-81.

Pinto, A.S., de Lana, M., Bastrenta, B., Barnabe, C., Quesney, V., Noel, S., Tibayrenc, M., 1998. Compared vectorial transmissibility of pure and mixed clonal genotypes of Trypanosoma cruzi in Triatoma infestans. Parasitology Research 84, 348-353.

Ramirez, J.D., Guhl, F., Rendon, L.M., Rosas, F., Marin-Neto, J.A., Morillo, C.A., 2010. Chagas cardiomyopathy manifestations and Trypanosoma cruzi genotypes circulating in chronic Chagasic patients. PLoS Neglected Tropical Diseases 4, e899.

Revollo, S., Oury, B., Laurent, J.P., Barnabe, C., Quesney, V., Carriere, V., Noel, S., Tibayrenc, M., 1998. Trypanosoma cruzi: impact of clonal evolution of the parasite on its biological and medical properties. Experimental Parasitology 89, 30-39.

Salomone, O.A. Basquiera, A.L. Sembaj, A. Aguerri, A.M. Reyes, M.E. Omelianuk, M., Fernandez, R.A., Enders, J., Palma, A., Barral, J.M., Madoery, R.J., 2003. Trypanosoma cruzi in persons without serologic evidence of disease, Argentina. Emerging Infectious Diseases 9, 1558-1562.

Tibayrenc, M., Breniere, F., Barnabe, C., Lemesre, J.L., Echalar, L., Desjeux, P., 1985. Isozymic variability of Trypanosoma cruzi: biological and epidemiological significance. Annales de la Societe Belge de Medecine Tropicale 65 (Suppl 1), 59-61.

Tibayrenc, M., Desjeux, P. 1983. The presence in Bolivia of two distinct zymodemes of Trypanosoma cruzi, circulating sympatrically in a domestic transmission cycle. Transactions of the Royal Society of Tropical Medicine and Hygiene 77, 73-75.

Tibayrenc, M., Neubauer, K., Barnabe, C., Guerrini, F., Skarecky, D., Ayala, F.J. 1993. Genetic characterization of six parasitic protozoa: parity between random-primer DNA typing and multilocus enzyme electrophoresis. Proceedings of the National Academy of Sciences of the United States of America 90 1335-1339.

Tibayrenc, M., Ward, P., Moya, A., Ayala, F.J., 1986. Natural populations of Trypanosoma cruzi, the agent of Chagas disease, have a complex multiclonal structure. Proceedings of the National Academy of Sciences of the United States of America 83, 115-119.

Toledo, M.J., Bahia, M.T., Carneiro, C.M., Martins-Filho, O.A., Tibayrenc, M., Barnabe, C., Tafuri, W.L., de Lana, M., 2003. Chemotherapy with benznidazole and itraconazole for mice infected with different Trypanosoma cruzi clonal genotypes. Antimicrobial Agents and Chemotherapy 47, 223-230.

Toledo, M.J., de Lana, M., Carneiro, C.M., Bahia, M.T., Machado-Coelho, G.L., Veloso, V.M., Barnabe, C., Tibayrenc, M., Tafuri, W.L., 2002. Impact of Trypanosoma cruzi clonal evolution on its biological properties in mice. Experimental Parasitology 100, 161-172.

Tomasini, N., Lauthier, J.J., Monje Rumi, M.M., Ragone, P.G., Alberti D’Amato, A.A., Perez Brandan, C., Cura, C.I., Schijman, A.G., Barnabe, C., Tibayrenc, M., Basombrio, M.A., Falla, A., Herrera, C., Guhl, F., Diosque, P., 2011. Interest and limitations of Spliced Leader Intergenic Region sequences for analyzing Trypanosoma cruzi I phylogenetic diversity in the Argentinean Chaco. Infection, Genetics and Evolution 11, 300-307.

Zafra, G., Mantilla,J.C., Jacome, J., Macedo, A.M., Gonzalez, C.I., 2011. Direct analysis of genetic variability in Trypanosoma cruzi populations from tissues of Colombian chagasic patients. Human Pathology 42, 1159-1168.

Zingales, B., Miles, M.A., Campbell, D.A., Tibayrenc, M., Macedo, A.M., Teixeira, M.M., Schijman, A.G., Llewellyn, M.S., Lages-Silva, E., Machado, C.R., Andrade, S.G., Sturm, N.R., 2012. The revised Trypanosoma cruzi subspecific nomenclature: rationale, epidemiological relevance and research applications. Infection, Genetics and Evolution 12, 240-253. 